\title{
Biological, biotechnological and chemical possibilities in reducing of grey mould (Botrytis cinerea) severity on strawberries
}

\author{
Biologiczne, biotechniczne i chemiczne możliwości \\ ograniczania szarej pleśni truskawki (Botrytis cinerea)
}

\author{
Urszula Wachowska*, Justyna Borowska, Edyta Kwiatkowska, Elżbieta Kowalska
}

\begin{abstract}
Summary
The objective of this study was to determine the efficacy of the Signum 33 WG (boscalid + piraclostrobin), Vaxiplant SL (laminarin) and a suspension of the yeast-like fungus Aureobasidium pullulans in controlling of the development of Botrytis cinerea on strawberry leaves, flowers and fruits. The experiments were carried out in vivo on strawberry leaves, under controlled conditions on flowering strawberry plants, and on a two-year plantation of strawberries cultivar Senga Sengana. Vaxiplant SL limited severity of grey mould on infested leaves and flowers, similarly as Signum 33 WG treatments and foliar application of $A$. pullulans suspension. On the strawberry plantation, all tested products didn't show statistical differences in control of grey mould severity. The applied protective treatments had no also significant effect on the average marketable strawberry yield.
\end{abstract}

Key words: strawberry; biological control; yeasts; laminarin; Botrytis cinerea

\section{Streszczenie}

Celem badań była ocena skuteczności preparatów Signum 33 WG (boskalid + piraklostrobina), Vaxiplant SL (laminaryna) oraz zawiesiny komórek grzyba Aureobasidium pullulans w ograniczeniu rozwoju Botrytis cinerea na liściach, kwiatach i owocach truskawki. Doświadczenia prowadzono w warunkach in vivo na liściach truskawki, na kwitnących roślinach truskawki w warunkach kontrolowanych oraz na dwuletniej plantacji truskawki odmiany Senga Sengana. Preparat Vaxiplant SL ograniczał powierzchnię porażenia liści i kwiatów przez grzyb $B$. cinerea, podobnie jak zabiegi ochronne wykonane fungicydem Signum 33 WG lub nalistnie zawiesiną komórek $A$. pullulans. Na plantacji truskawki odmiany Senga Sengana żaden z zastosowanych preparatów nie ograniczył istotnie nasilenia szarej pleśni. Zabiegi ochronne nie miały także istotnego wpływu na plonowanie truskawki.

Słowa kluczowe: truskawka; biologiczna ochrona; drożdże; laminaryna; Botrytis cinerea

\author{
Uniwersytet Warmińsko-Mazurski w Olsztynie \\ Katedra Fitopatologii i Entomologii \\ Prawocheńskiego 17, 10-720 Olsztyn \\ *corresponding author: urszula.wachowska@uwm.edu.pl
}




\section{Wstęp / Introduction}

Grzyb Botrytis cinerea Pers. Ex. Fr. poraża kwiaty truskawki prowadząc do ich zamierania, jak również owoce, czego następstwem są objawy typowej dla szarej pleśni zgnilizny widocznej w czasie ich dojrzewania, transportowania i przechowywania (Helbig 2002). Jednym ze sposobów ochrony truskawek przed szarą pleśnią jest ochrona chemiczna. Jednak zbyt częste stosowanie fungicydów o podobnym mechanizmie działania może prowadzić do powstawania form odpornych tego patogenu (Diánez i wsp. 2002). Nowe uregulowania prawne (Dz.U. 2013, poz. 455) wskazujące na konieczność stosowania integrowanej ochrony roślin przez wszystkich profesjonalnych użytkowników środków ochrony roślin oraz wzrastające wymagania konsumentów, skłaniają do poszukiwania alternatywnych metod ochrony. Jedną z nich może być metoda biologiczna, w której wykorzystywane są np. drożdże indukujące mechanizmy obronne roślin lub konkurujące o przestrzeń i składniki odżywcze $\mathrm{z}$ patogenami (Ippolito i wsp. 2000; Castoria i wsp. 2001; Droby i wsp. 2002; Helbig 2002; Wang i wsp. 2009). Zwiększa się także zainteresowanie stymulatorami odporności roślin (Matysiak i Adamczewski 2009). Jednym z nich jest preparat Vaxiplant SL zawierający laminarynę, wyciąg z listownicy palczastej (Laminaria digitala).

Celem badań była ocena skuteczności preparatów Signum 33 WG, Vaxiplant SL oraz zawiesiny komórek grzyba Aureobasidium pullulans w ograniczeniu rozwoju $B$. cinerea na liściach, kwiatach i owocach truskawki.

\section{Materiały i metody / Materials and methods}

Testowano wpływ temperatury na wzrost izolatu $A$. $p u$ llulans, pochodzącego z liści pszenicy ozimej, na podłożu glukozowo-ziemniaczanym. Celem badań było wykluczenie możliwości rozwoju tego izolatu w temperaturze ciała zwierząt stałocieplnych. Na pożywkę w płytkach Petriego nanoszono po $100 \mu \mathrm{l}$ zawiesiny izolatu A. pullulans o gęstości $10^{2}$ komórek w $1 \mathrm{~cm}^{3}$ wody. Po czterech dobach inkubacji w temperaturze $4,14,24 \mathrm{i} 35^{\circ} \mathrm{C}$ liczono kolonie grzyba, a następnie dokonano transformacji danych zgodnie ze wzorem log (liczba kolonii +1$)$.

Ocenę skuteczności A. pullulans oraz Vaxiplant SL w ograniczeniu nasilenia szarej pleśni przeprowadzono na liściach z roślin truskawki odmiany Senga Sengana. Końce liści (po 5 w każdej kombinacji) zanurzano w wodnej zawiesinie grzyba $A$. pullulans o gęstości $10^{6}$ komórek w $1 \mathrm{~cm}^{3}$ wody lub preparacie Vaxiplant SL o stężeniu roztworu $0,25 \%$. Następnie liście umieszczono na wilgotnej bibule w szklanych płytkach Petriego o średnicy $9 \mathrm{~cm}$, po 24, 38, 72 i 96 godzinach, na szczytach liści wyłożono 5 mm krążki podłoża glukozowo-ziemniaczanego przerośniętego 7-dniową grzybnią B. cinerea. Kombinację kontrolną stanowiły liście zanurzone w sterylnej wodzie i inokulowane patogenem. Doświadczenie założono w pięciu powtórzeniach. Po siedmiu dobach inkubacji w ciemności, w temperaturze $24^{\circ} \mathrm{C}$ zmierzono powierzchnię liści i powstałych nekroz stosując program ImageJ $1.48 \mathrm{p}$. Wyniki przedstawiono jako procent powierzchni nekroz w stosunku do całej powierzchni liścia.

Określono również skuteczność izolatu A. pullulans oraz preparatów Vaxiplant SL i Signum 33 WG w ograniczeniu porażenia kwiatów truskawki przez $B$. cinerea. Do doniczek o średnicy $12 \mathrm{~cm}$, wypełnionych ziemią ogrodniczą wymieszaną z piaskiem $\mathrm{w}$ proporcjach 1:1, wysadzono sadzonki truskawki odmiany Senga Sengana. Rośliny umieszczono w fitotronie i podlewano roztworem Hoeglanda. Rośliny rosły w warunkach $70-80 \%$ wilgotności względnej powietrza i temperaturze $23^{\circ} \mathrm{C}$ w dzień oraz $16^{\circ} \mathrm{C}$ w nocy, przy 12 -godzinnym naświetlaniu w dzień. Po dwóch tygodniach kwiaty (po pięć na roślinie) zainokulowano zawiesiną $B$. cinerea o gęstości $10^{4}$ w $1 \mathrm{~cm}^{3}$ zmytą z 7-dniowych kolonii. Inokulacja patogenem została przeprowadzona po 48 godzinach od zabiegu (Ap L) lub podlania (Ap S) roślin izolatem A. pullulans o gęstości $10^{6}$ komórek w $1 \mathrm{~cm}^{3}$ wody, opryskania roślin preparatem Vaxiplant SL w stężeniu $0,25 \%$ lub fungicydem Signum 33 WG w stężeniu 0,36\%. Kontrolę stanowiły rośliny nieopryskiwane. Ocenę stopnia porażenia kwiatów przeprowadzono po siedmiu dniach od momentu inokulacji patogenem, określając procent powierzchni porażonych kwiatów (wprowadzenie ich obrazów do pamięci komputera) stosując program ImageJ 1.48p. Doświadczenie przeprowadzono w trzech powtórzeniach.

W latach 2012 i 2013 oceniono wpływ zabiegów ochronnych na plonowanie i zdrowotność roślin truskawki odmiany Senga Sengana posadzonych w sierpniu 2011 roku w ogrodzie doświadczalnym Uniwersytetu WarmińskoMazurskiego w Olsztynie. Rośliny wysadzono w odstępach $90 \mathrm{~cm}$, każde poletko stanowiły 4 rośliny. Rośliny opryskiwano 4-krotnie zapobiegawczo (Ap L) lub podlewano (Ap S) zawiesiną izolatu A. pullulans o stężeniu $10^{6}$ w $1 \mathrm{~cm}^{3}$, co 6-7 dni rozpoczynając od fazy początku kwitnienia roślin do dojrzewania owoców. Kombinację porównawczą stanowiły rośliny opryskiwane dwukrotnie w okresie kwitnienia środkiem Signum 33 WG (boskalid + piraklostrobina) w dawce $18 \mathrm{~g} / 100 \mathrm{~m}^{2}$ oraz czterokrotnie preparatem Vaxiplant SL zastosowanym w dawce $15 \mathrm{~g} / 100 \mathrm{~m}^{2}$. Kontrolę stanowiły rośliny nieopryskiwane. Doświadczenie założono w czterech powtórzeniach. Owoce truskawki zbierano trzykrotnie: 13 (I), 19 (II) i 24 (III) czerwca 2013 roku. Na wszystkich roślinach w kombinacjach policzono i zważono owoce zdrowe oraz chore.

Uzyskane dane, dotyczące liczebności A. pullulans oznaczonej metodą hodowlaną transformowano logarytmicznie zgodnie ze wzorem log (jednostki tworzące kolonie +1 ). Powierzchnię zmian chorobowych oszacowano analizując obrazy porażonych liści i kwiatów programem ImageJ 1.48p. Skuteczność ochrony oszacowano według wzoru Abbotta (Abbott 1925). Analizę wariancji przeprowadzono $\mathrm{z}$ wykorzystaniem programu STATISTICA v. 9.0. Test Duncana $(\mathrm{p}=0,01)$ zastosowano dla określenia istotności różnic między plonowaniem roślin, liczebnością porażonych owoców oraz między średnim nasileniem objawów chorobowych na liściach i kwiatach (procent powierzchni nekroz liści i kwiatów w stosunku do całej powierzchni). 


\section{Wyniki i dyskusja / Results and discussion}

Najbardziej intensywny wzrost izolatu $A$. pullulans zaobserwowano $\mathrm{w}$ temperaturze $24^{\circ} \mathrm{C}$ na podłożu glukozowo-ziemniaczanym (rys. 1). W temperaturze 4 i $35^{\circ} \mathrm{C}$ grzyb nie rozwijał się. W doświadczeniu na odciętych liściach preparat Vaxiplant SL istotnie ograniczył powierzchnię porażenia liści przez $B$. cinerea tylko w czasie $48 \mathrm{~h}$ między naniesieniem preparatu a inokulacją liści (tab. 1). Jego skuteczność wyniosła wówczas 36,5\%. Natomiast w czasie 72 i 96 godzin, skuteczność środka Vaxiplant SL wyniosła odpowiednio 8,7 i $11,1 \%$ i nie różniła się istotnie od porażenia liści kontrolnych. Zastosowanie zawiesiny grzyba $A$. pullulans nie wpłynęło na ograniczenie porażenia liści przez $B$. cinerea (tab. 1).

$\mathrm{W}$ prezentowanych badaniach liście truskawki traktowane preparatem Vaxiplant SL wykazywały zdecydowanie silniejszą i szybszą reakcję obronną w porównaniu $\mathrm{z}$ dynamiką reakcji obronnych wzbudzonych zawiesiną komórek izolatu A. pullulans. W czasie 48 godzin między naniesieniem tego preparatu na liście a inokulacją $B$. cinerea zanotowano istotnie mniejsze porażenie liści $\mathrm{w}$ porównaniu do liści kontrolnych. Można wnioskować, że w liściach nastąpiło uruchomienie mechanizmów obronnych. Laminaryna zawarta w preparacie Vaxiplant SL jest polisacharydem, który wykazuje takie właściwości (Matysiak i Adamczewski 2009). Antagonistyczny grzyb A. pullulans nie ograniczył porażenia liści. Natomiast Ippolito i wsp. (2000) wykazali wpływ A. pullulans na indukowanie odporności jabłoni, na co wskazywały ograniczone objawy porażenia jabłek przez $B$. cinerea i Penicillium expansum. Po 24 godzinach od zastosowania zawiesiny, w tkankach roślin wzrastała aktywność $\beta$-1,3glukanazy, chitynazy i peroksydazy. $\mathrm{W}$ badaniach prowadzonych nad innymi czynnikami pełniącymi rolę antagonistów, np. Cryptococcus laurentii czy jasmonian metylu w zapobieganiu chorób przechowalniczych brzoskwini, już po 24 godzinach obserwowano wzrost aktywności $\beta$-1,3-glukanazy, peroksydazy oraz amoniakoliazy fenyloalaniny $\mathrm{w}$ temperaturze $25^{\circ} \mathrm{C}$ (Yao i Tian 2005).

Zastosowanie preparatu Vaxiplant SL na kwitnace rośliny $\mathrm{w}$ fitotronie ograniczyło o $47,5 \%$ porażenie kwiatów w porównaniu $\mathrm{z}$ kombinacją kontrolną $(\mathrm{Bc})$, inokulowaną B. cinerea (rys. 2). Podobny efekt uzyskano również po zabiegach wykonanych fungicydem Signum 33 WG lub nalistnie zawiesiną $A$. pullulans. Natomiast po zastosowaniu zawiesiny $A$. pullulans doglebowo, obserwowano więcej porażonych kwiatów niż w kombinacji kontrolnej (rys. 2).

Tabela 1. Porażenie blaszki liściowej truskawki (procent powierzchni liścia)

Table 1. Infection of strawberry leaf (percentage of leaf area)

\begin{tabular}{l|c|c|c|c}
\hline \multirow{2}{*}{$\begin{array}{c}\text { Zabiegi } \\
\text { Treatments }\end{array}$} & \multicolumn{4}{|c}{$\begin{array}{c}\text { Czas (godziny) od naniesienia preparatów do inokulacji liści } \\
\text { Time (hours) since product application to leaf inoculation }\end{array}$} \\
\cline { 2 - 5 } & 24 & 48 & 72 & 96 \\
\hline Kontrola - Control & $74,0 \mathrm{~b}$ & $93,4 \mathrm{a}$ & $86,9 \mathrm{ab}$ & $82,8 \mathrm{ab}$ \\
\hline Aureobasidium pullulans & $90,3 \mathrm{ab}$ & $94,5 \mathrm{a}$ & $84,6 \mathrm{ab}$ & $95,8 \mathrm{ab}$ \\
\hline Vaxiplant SL & $83,5 \mathrm{ab}$ & $60,2 \mathrm{~b}$ & $79,4 \mathrm{ab}$ & $68,7 \mathrm{ab}$ \\
\hline
\end{tabular}

Jednakowymi literami oznaczono wartości nieróżniące się istotnie według testu Duncana $(\mathrm{p}=0,01)$

Values determined identical letters do not differ significantly according to the Duncan test $(\mathrm{p}=0.01)$

Tabela 2. Wpływ różnych metod ochrony na plonowanie truskawek

Table 2. Effect of different methods of protection on the yield of strawberries

\begin{tabular}{|c|c|c|c|c|c|c|c|c|}
\hline \multirow{2}{*}{$\begin{array}{l}\text { Zabiegi } \\
\text { Treatments }\end{array}$} & \multicolumn{4}{|c|}{$\begin{array}{l}\text { Masa zdrowych owoców z rośliny w gramach } \\
\text { Weight of healthy fruits per plant in grams }\end{array}$} & \multicolumn{4}{|c|}{$\begin{array}{l}\text { Procent owoców zdrowych z rośliny } \\
\text { Percent of healthy fruit per plant }\end{array}$} \\
\hline & I & II & III & $\begin{array}{c}\text { średnio } \\
\text { average } \\
\text { I-III }\end{array}$ & I & II & III & $\begin{array}{c}\text { średnio } \\
\text { average } \\
\text { I-III }\end{array}$ \\
\hline $\mathrm{C}$ & $191,7 \mathrm{ab}$ & $182,5 \mathrm{ab}$ & $137,3 \mathrm{ab}$ & $170,5 \mathrm{~A}$ & $90,9 \mathrm{ab}$ & $93,7 \mathrm{ab}$ & $91,9 \mathrm{ab}$ & $92,1 \mathrm{~A}$ \\
\hline Ap (S) & $230,4 \mathrm{a}$ & $250,0 \mathrm{a}$ & $74,5 \mathrm{bc}$ & $185,0 \mathrm{~A}$ & $93,6 \mathrm{ab}$ & $96,0 \mathrm{ab}$ & $89,3 \mathrm{ab}$ & $93,4 \mathrm{~A}$ \\
\hline Ap (L) & $244,4 \mathrm{a}$ & $226,0 \mathrm{a}$ & $205,5 \mathrm{a}$ & $225,3 \mathrm{~A}$ & $91,9 \mathrm{ab}$ & $96,0 \mathrm{ab}$ & $90,5 \mathrm{ab}$ & $92,1 \mathrm{~A}$ \\
\hline Sig & $171,7 \mathrm{ab}$ & $170,2 \mathrm{ab}$ & $151,2 \mathrm{abc}$ & $164,3 \mathrm{~A}$ & $91,8 \mathrm{~b}$ & $97,3 \mathrm{~b}$ & $91,3 \mathrm{ab}$ & $92,8 \mathrm{~A}$ \\
\hline Vax & $170,3 \mathrm{ab}$ & $159,0 \mathrm{abc}$ & $51,7 \mathrm{c}$ & $127,0 \mathrm{~A}$ & $93,4 \mathrm{ab}$ & $95,5 \mathrm{ab}$ & $86,4 \mathrm{~b}$ & $91,1 \mathrm{~A}$ \\
\hline $\begin{array}{l}\text { Średnio } \\
\text { Average }\end{array}$ & 200,2 B & $194,76 \mathrm{~B}$ & $126,6 \mathrm{~A}$ & & 92,3 B & 95,6 B & $90,3 \mathrm{~A}$ & \\
\hline
\end{tabular}

Wyjaśnienia jak w tabeli 1. - Explanations as in Table 1

C - kontrola - control; Ap (S) - Aureobasidium pullulans (doglebowo - soil); Aureobasidium pullulans (liść - leaves); Sig - Signum 33 WG; Vax Vaxiplant SL

I, II, III - terminy zbiorów - harvest dates 
Tabela 3. Procent owoców truskawki porażonych przez Botrytis cinerea

Table 3. Percent of strawberry fruit infected with Botrytis cinerea

\begin{tabular}{l|c|c|c|c}
\hline \multirow{2}{*}{ Zabiegi-Treatments } & \multicolumn{3}{|c}{ Termin zbioru owoców - Harvest fruit date } & $\begin{array}{c}\text { średnio } \\
\text { average } \\
\text { I-III }\end{array}$ \\
\cline { 2 - 5 } & I & II & III & $7,9 \mathrm{~A}$ \\
\hline $\mathrm{C}$ & $9,1 \mathrm{ab}$ & $6,3 \mathrm{ab}$ & $8,1 \mathrm{ab}$ & $6,6 \mathrm{~A}$ \\
\hline $\mathrm{Ap}(\mathrm{S})$ & $6,4 \mathrm{ab}$ & $4,0 \mathrm{ab}$ & $9,7 \mathrm{ab}$ & $7,9 \mathrm{~A}$ \\
\hline $\mathrm{Ap}(\mathrm{L})$ & $8,1 \mathrm{ab}$ & $4,0 \mathrm{~b}$ & $8,7 \mathrm{ab}$ & $7,2 \mathrm{~A}$ \\
\hline Sig & $8,2 \mathrm{ab}$ & $2,7 \mathrm{~b}$ & $13,6 \mathrm{ab}$ & $8,9 \mathrm{~A}$ \\
\hline Vax & $6,6 \mathrm{ab}$ & $4,5 \mathrm{~b}$ & $9,7 \mathrm{~A}$ & - \\
\hline Średnio-Average & $7,7 \mathrm{~B}$ & $4,4 \mathrm{~B}$ & & \\
\hline
\end{tabular}

Wyjaśnienia jak w tabeli 2. - Explanations as in Table 2

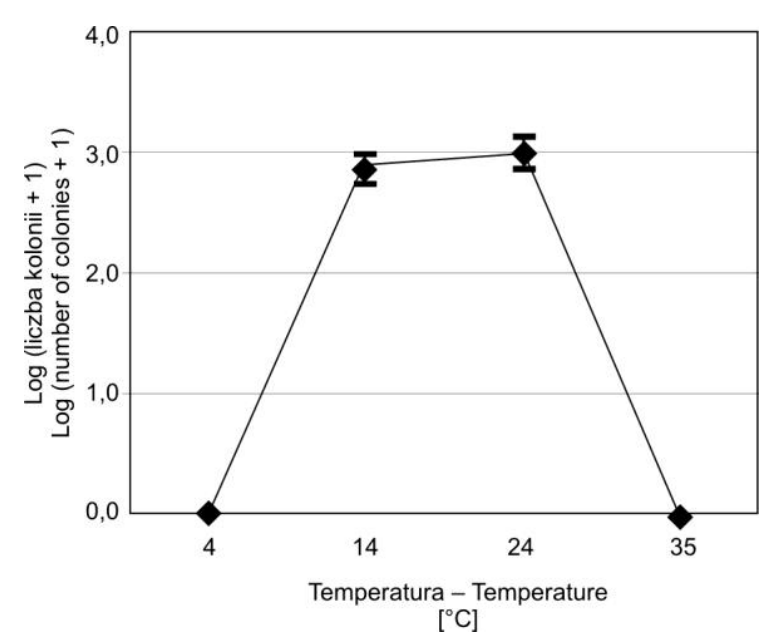

Rys. 1. Rozwój Aureobasidium pullulans w różnych temperaturach na podłożu glukozowo-ziemniacznym

Fig. 1. Development of Aureobasidium pullulans at different temperatures on the PDA medium

W badaniach polowych wykazano, że żaden z zastosowanych preparatów nie wpłynął istotnie na zwiększenie plonowania roślin truskawek (tab. 2). Także liczba zdrowych owoców była podobna do tych $\mathrm{z}$ roślin kontrolnych (tab. 2). Nie stwierdzono istotnie mniejszej liczby porażonych owoców po zastosowaniu środków Signum 33 WG i Vaxiplant SL oraz zwiesiny A. pullulans (tab. 3). Jedynie w czasie I i II zbioru porażenie owoców na roślinach chronionych badanymi preparatami było nieznacznie mniejsze niż na kontrolnych. W przedstawionych badaniach skuteczność nalistnej aplikacji zawiesiny A. pullulans była większa w ograniczeniu porażenia kwiatów niż liści. Można przypuszczać, że w tym przypadku dominu jącym mechanizmem działania antagonisty była konku-

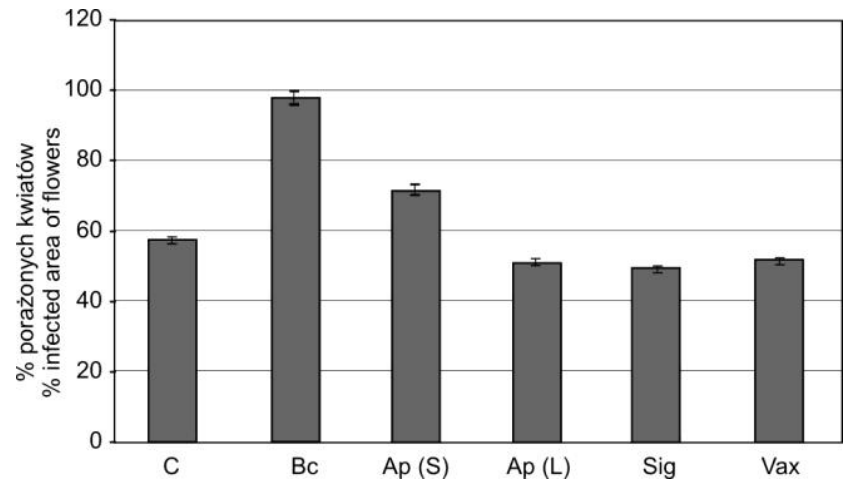

C - kontrola (nieinokulowana) - control (not inoculated); Bc - kontrola inokulowana przez Botrytis cinerea - control inoculated by Botrytis cinerea; $\mathrm{Ap}(\mathrm{S})$ - Aureobasidium pullulans (doglebowo - soil); Ap (L) - Aureobasidium pullulans (liście - leaves); Sig - Signum 33 WG; Vax - Vaxiplant SL

Rys. 2. Procent zainfekowanej powierzchni kwiatów

Fig. 2. The percentage of infected area of flowers

rencja o składniki odżywcze z $B$. cinerea, czego dowiodły także wcześniejsze badania (Castoria i wsp. 2001; Elad i Stewar 2007).

\section{Wnioski / Conclusions}

1. Signum $33 \mathrm{WG}$, Vaxiplant SL oraz grzyb A. pullulans stosowany dolistnie ograniczyły porażenie kwiatów truskawki przez $B$. cinerea.

2. Vaxiplant SL ograniczał również porażenie liści przez B. cinerea.

3. Żaden $\mathrm{z}$ zastosowanych preparatów nie ograniczył istotnie porażenia owoców truskawki i nie zwiększył plonowania roślin.

\section{Literatura / References}

Abbott W.S. 1925. A method of computing the effectiveness of an insecticide. Journal of Economic Entomology 18: $265-267$.

Castoria R., de Curtis F., Lima G., Caputo L., Pacifico S., de Cicco V. 2001. Aureobasidium pullulans (LS-30) an antagonist of postharvest pathogens of fruits: study on its modes of action. Postharvest Biology and Technology 22: 7-17.

Diánez F., Santos M., Blanco R., Tello J.C. 2002. Fungicide resistance in Botrytis cinerea isolates from strawberry crops in Huelva (Soutwestern Spain). Phytoparasitica 30 (5): 529-534. 
Droby S., Vinokur V., Weiss B., Cohen L., Daus A., Goldschmidt E.E., Porat R. 2002. Induction of resistance to Penicillium digitatum in grapefruit by the yeast biocontrol agent Candida oleophila. Phythopathology 92 (4): 393-399.

Dz.U. 2013, poz. 455. Ustawa z dnia 8 marca 2013 r. o środkach ochrony roślin. Dyrektywa 2009/128 WE.

Elad Y., Stewar A. 2007. Microbial control of Botrytis spp. p. 223-241. In: "Botrytis: Biology, Pathology and Control” (Y. Elad, B. Williamson, P. Tudzynski, F. Delen, eds.). Springer, 393 pp.

Helbig J. 2002. Ability of the antagonistic yeast Cryptococcus albidus to control Botrytis cinerea in strawberry. BioControl 47: 85-99.

Ippolito A., El Ghaouth A., Wilson C.L., Wisniewski M. 2000. Control of postharvest decay of apple fruit by Aureobasidium pullulans and induction of defense responses. Postharvest Biology and Technology 19: 265-272.

Matysiak K., Adamczewski K. 2009. Regulatory wzrostu i rozwoju roślin - kierunki badań w Polsce i na świecie. [Plant growth regulators application - studies in Poland and in the world]. Progress in Plant Protection/Postępy w Ochronie Roślin 49 (4): $1810-1816$.

Wang W., Chi Z., Liu G., Buzdar M.A., Chi Z., Gu Q. 2009. Chemical and biological characterization of siderophore produced by the marine-derived Aureobasidium pullulans HN6.2 and its antibacterial activity. Biometals 22 (6): 965-972.

Yao H.J., Tian S.P. 2005. Effects of a biocontrol agent and methyl jasmonate on postharvest diseases of peach fruit and the possible mechanisms involved. Journal of Applied Microbiology 98: 941-950. 